\title{
10
}

\section{New Capabilities and Nuclear Deterrence in Europe}

\author{
Łukasz Kulesa
}

By and large, Europeans treat the nexus between new technologies and nuclear deterrence with suspicion rather than optimism. European countries and the European Union (EU) are more than happy to aspire to leadership in the civilian part of the ongoing technological revolution. European militaries and the armament industry are busy looking for next-generation capabilities for future conventional weapon systems. ${ }^{1}$ Yet, to the extent that the evolution of the relationship between nuclear weapons and new military technologies is discussed beyond military experts, it is primarily seen as a risk factor. ${ }^{2}$

Further complicating the picture are the differences regarding views on deterrence inside Europe. A 2018 study by the European Council on Foreign Affairs divided the European NATO members into four categories: True Believers in nuclear deterrence (e.g. France and the United Kingdom but also Poland and Romania), the Conflicted (e.g. Germany), the Pragmatists (who accept without enthusiasm its necessity) and the

1 This includes sixth-generation combat air systems, FCAS and Tempest, or an array of projects developed in the framework of the European Defence Fund and the EU's Permanent Structural Cooperation. See 'About Pesco', Pesco, accessed 14 September 2021, pesco.europa.eu/.

2 See Katarzyna Kubiak, Sylvia Mishra and Graham Stacey, 'Nuclear Decision-Making under Technological Complexity', European Leadership Network, March 2021, www.europeanleadership network.org/wp-content/uploads/2021/03/ELN-Pilot-Workshop-Report-1.pdf. 
Conformists (the largest and most passive group). ${ }^{3}$ The 'deterrence IQ' within the alliance is therefore not evenly distributed, and 'emerging technologies IQ' even less so. In some countries there is considerable hesitation to discuss not only the nuclear dimension, but also broader requirements for deterrence and escalation management.

\section{Conventional Deterrence Nexus and the Role of New Technologies}

European ambivalence about the impact of new technologies on deterrence stems from several sources. Generally speaking, there is widespread scepticism within the political classes about the ability of new military technology to assist in resolving major contemporary strategic dilemmas, such as the West's relationship with Russia and China. Political, economic, technological and societal factors are seen as far more important aspects bearing on the future of these relationships than military power. This may be best demonstrated in Europe's lack of interest in territorial ballistic missile defence.

A substantial segment of government and expert communities share the view that the emergence and deployment of new capabilities would become a source of heightened instability both at the global level and in the European context. This includes concerns about the security and safety of existing nuclear weapons systems and command and control infrastructure (especially their vulnerability to cyber interference), the perils of the development of fully autonomous or artificial intelligenceenabled strategic systems, the destabilising effects of the misuse of social media and escalation in deepfakes, and an inadvertent escalation from conventional to nuclear conflict due to the entanglement of nuclear and non-nuclear systems. ${ }^{4}$

There also is a doctrinal 'firewall' between nuclear weapons and other means of deterrence in the strategies of two European nuclear possessors: the UK and France. This thinking seems to be also influencing the

3 Manuel Lafont Rapnouil, Tara Varma and Nick Witney, 'Eyes Tight Shut: European Attitudes towards Nuclear Deterrence', European Council on Foreign Relations, Flash Scorecard, December 2018, www.ecfr.eu/page/-/ECFR_275_NUCLEAR_WEAPONS_FLASH_SCORECARD_update.pdf.

4 See, for example, research cited in: Andrew Futter and Benjamin Zala, 'Strategic Non-Nuclear Weapons and the Onset of a Third Nuclear Age', European Journal of International Security 6(3), 2021, 8-10, doi.org/10.1017/eis.2021.2. 
conceptual approach of NATO. From the political viewpoint, maintaining firm control over decisions on the employment of nuclear weapons and separating these from conventional elements of deterrence posture remain of paramount importance for most members of NATO.

\section{The Russian Challenge for NATO}

Europeans' scepticism regarding the strategic value of new capabilities does not make them impervious to specific challenges in this area stemming from Russia. European states have already been subjected to a number of Russia-originated cyber attacks and remain in range of Russian short and intermediate-range, precision-guided missiles. In 2017, Russia reportedly used one of its satellites to intercept transmissions from the French-Italian satellite, demonstrating the potential to conduct assertive space operations. ${ }^{5}$

Russia has shown determination in integrating a broad set of approaches, tactics and capabilities to reach the desired strategic effect. Some past pronouncements of the Russian military leadership pointed to the aspiration of gradually reducing the reliance on nuclear weapons through development of 'non-nuclear deterrence' forces-understood primarily as long-range, conventional, precision-guided ballistic cruise and hypersonic systems. However, subsequent developments suggested instead a drive to advance in parallel in a range of domains, including conventional, nuclear, cyber and electronic warfare, space capabilities, and air and missile defence, as well as military implementation of emerging technologies such as artificial intelligence. ${ }^{6}$ New technologies are also utilisedalongside other means - for grey-zone activities and for probing NATO and national responses.

In any crisis or conflict with NATO, Russia would not only aim to maximise the effects of its possession of nuclear weapons (which should not be reduced to early use of non-strategic weapons options), but also pursue confrontation in multiple domains simultaneously, aiming to capture the strategic initiative and bring a quick end to the conflict on favourable

5 'Russia "Tried to Spy on France in Space"-French Minister', BBC News, 7 September 2018, www.bbc.com/news/world-europe-45448261.

6 The evolution is described in: Kristin Ven Bruusgaard, 'Russian Nuclear Strategy and Conventional Inferiority', Journal of Strategic Studies 44(1), October 2020, 3-35, doi.org/10.1080/01402390. 2020.1818070 . 
terms. ${ }^{7}$ Such a posture is partly grounded in a sense of vulnerability; Russia remains convinced that US technological breakthroughs give it an advantage in conflict, including the ability to attack Russias command and control system and/or its nuclear assets and thus prevent nuclear retaliation, and that some US non-nuclear strategic systems have been developed with this decapitation goal in mind.

\section{European Responses}

Against such an opponent, the survivability of nuclear forces, and maintaining the ability to resort to their use and successfully execute a nuclear strike, becomes paramount. France and the UK are therefore looking into safeguarding their nuclear systems against the use of new technologies by Russia and any other actors. This includes increasing the resilience of their command and control system and aspects of cybersecurity, and avoiding detection of their ballistic missile-carrying submarines. France is exercising the air component of its nuclear forces to be able to overcome a modern air defence system utilising a whole range of countermeasures and new technologies. Both countries are also planning to incorporate new technologies into their future nuclear systems, including new designs for submarines (e.g. the UK's Dreadnought class and France's SNLE $3 \mathrm{G}$ program). In the case of France, its next-generation nuclear cruise missile (the ASN4G) is to utilise hypersonic technologies. The UK's new nuclear warheads, to be developed jointly with the US, are to include an improved set of penetration aids allowing them to overcome existing and prospective missile defence systems.

France and the UK are investing heavily in new non-nuclear capabilities, and multi-domain integration is seen by both as essential for the modern battlefield. At the same time, both countries treat nuclear deterrence as the only credible response to major threats to vital national interests, and the nuclear dimension is seen as being complemented, but not replaced by non-nuclear capabilities. As highlighted by French President Emmanuel Macron in a 2020 speech, 'conventional military manoeuvre[s]' can be used for deterrence purposes, but nuclear deterrence remains the key to France's security and freedom of action, as it 'prevents adversaries from

7 On the role of nuclear versus non-nuclear forces in escalation, see M. Kofman, A. Fink and J. Edmonds, 'Russian Strategy for Escalation Management', CNA, April 2020, 18-29. 
betting on escalation, intimidation and blackmailing to achieve their ends' ${ }^{8}$ This is further elaborated in France's security doctrine, which describes the objective of French nuclear forces as preventing conventional forces from being circumvented 'from above' through escalation.

The UK, in its March 2021 Integrated Review, announced an increase in the salience of nuclear weapons. The document envisages raising the cap on UK nuclear warheads from 180 to 260 and limiting transparency on warhead and missile deployment numbers. This was justified by 'recognition of the evolving security environment, including the developing range of technological and doctrinal threats.? While the document focuses on the development of nuclear doctrine and the capabilities of potential adversaries as the reason for the shift, the change may also be related to concerns about the long-term effect of non-nuclear systems on the credibility of British deterrence. UK Secretary of State for Defence Ben Wallace subsequently mentioned advances in Russian ballistic missile systems as having influenced the UK's decision to raise its warhead numbers-a likely reference to Moscow's defence system, which incorporates both nuclear and non-nuclear elements. The document includes the caveat that the UK can review its negative security assurances (i.e. its pledge not to use nuclear weapons) if 'emerging technologies that could have a comparable impact [to nuclear weapons use]' make it necessary.

NATO is in the process of adapting to the challenges and opportunities brought by the growing pace of developments in the emerging and disruptive technologies (EDT) area. The alliance has been slow to address the challenges and consequences of its deterrence posture and relationship with Russia. It was preoccupied in the 2010s, first and foremost with establishing a forward deployment posture along its eastern flank, increasing the availability of conventional forces and their level of readiness and mobility. This was accompanied by an increased focus on countering 'hybrid warfare' activities below the threshold of war, including

8 'Speech of the President of the Republic Emmanuel Macron on the Defense and Deterrence Strategy', France Diplomacy, 7 February 2020, www.diplomatie.gouv.fr/en/french-foreign-policy/ security-disarmament-and-non-proliferation/news/2020/article/speech-of-the-president-of-therepublic-emmanuel-macron-on-the-defense-and.

9 Global Britain in a Competitive Age. The Integrated Review of Security, Defence, Development and Foreign Policy, March 2021, 76, assets.publishing.service.gov.uk/government/uploads/system/uploads/ attachment_data/file/969402/The_Integrated_Review_of_Security_Defence_Development_and_ Foreign_Policy.pdf. 
the malign use of cyberspace (recognised only in 2016 by NATO as an operational domain) and disinformation. Towards the end of the 2010s, high-level political interest in EDT surged, fuelled internally by the US's promotion of the effects of its third offset strategy and externally by a growing realisation of the technological advances made by potential adversaries. In 2019, NATO's EDT roadmap was adopted. A major report by the NATO Science and Technology Organization, published in March 2020, built on the roadmap, identifying eight EDTs considered to be 'major strategic disruptors' for the period 2020-40: data, artificial intelligence, autonomy, space, hypersonics, quantum, biotechnology and materials. ${ }^{10}$ The report drew attention to the need to look at these technologies comprehensively, as their effects will be augmented through the integration and interactions between them. Still, as noted by the NATO 2030 Reflection Group, the alliance needs a 'strategic surge' in this area, more cooperation with the private sector and to firmly anchor EDT in its strategic thinking, planning and operations. ${ }^{11}$

The impact of specific EDT and/or their cumulative weight on NATO's nuclear deterrence have been noted. Examples include the ability to use improved sensors and big data analysis to locate allies' nuclear delivery systems, and the capacity of hypersonic systems to deliver successful strikes against high-value NATO targets without crossing the nuclear threshold, which would have 'potentially profoundly destabilising' effects. ${ }^{12}$ These considerations had probably already had an impact on the operational side of NATO's nuclear mission in terms of updating nuclear, command, control and communication systems against cyber and other forms of interference; ${ }^{13}$ identifying ways to increase the survivability of nuclear assets assigned to NATO during a potential conflict; and conducting nuclear-related exercises. However, so far they have not altered NATO's strategy regarding the role of nuclear weapons or the function of

10 Science and Technology Trends 2020-2040. Exploring the S\&T Edge, NATO, Science and Technology Organization, March 2020, www.nato.int/nato_static_fl2014/assets/pdf/2020/4/ pdf/190422-ST_Tech_Trends_Report_2020-2040.pdf.

11 NATO 2030: United for a New Era, Analysis and Recommendations of the Reflection Group Appointed by the NATO Secretary General, November 2020, www.nato.int/nato_static_fl2014/assets/ pdf/2020/12/pdf/201201-Reflection-Group-Final-Report-Uni.pdf.

12 Science and Technology Trends, 91.

13 See Y. Afina, C. Inverarity and B. Unal, Ensuring Cyber Resilience in NATO's Command, Control and Communications Systems, Chatham House Research Paper, July 2020, www.chathamhouse.org/sites/ default/files/2020-07-17-cyber-resilience-nato-command-control-communication-afina-inverarityunal_0.pdf. 
new capabilities in deterrence and in managing escalation. The preparation of NATO's new strategic concept, scheduled to be finished in 2022, could provide an opportunity to address these issues.

\section{Consequences for NATO and the Relations of European Allies with the US}

The impact of new technologies and emerging military capabilities on nuclear deterrence is the subject of intense debate among experts, with multiple and often contradictory hypotheses. ${ }^{14}$ Some assert that the nature of nuclear deterrence will be radically transformed and that the increased vulnerability of nuclear systems and improved defences will lead to the role of nuclear weapons becoming marginalised, an increase in the number of nuclear weapons or the adoption of more dangerous nuclear postures by some possessors (e.g. pre-delegation, launch-on-warning, pre-emption). But there are also more conservative predictions-namely that new technologies may not fully deliver on their disruptive promises and/or that their offensive advantages would be balanced by defensive countermeasures, leaving the role of nuclear deterrence more or less intact.

The analysis conducted so far in this chapter seems to indicate that the European True Believers (in nuclear deterrence) remain unconvinced that any radical changes are approaching. The UK and France are taking steps to safeguard the functioning of their nuclear deterrence in a more challenging environment, utilising the assistance of new technologies. But they continue to see the role of nuclear weapons as 'ultima ratio' in escalation management and retaliation, to which no comparable alternative is likely to emerge. This is likely to remain the default position.

The future trajectory of development and deployment of new non-nuclear capabilities by the US will have an impact on the alliance's nuclear deterrence posture, especially regarding the rationale for maintaining US forward-deployed nuclear forces in Europe and continuing NATO's nuclear sharing. If US non-nuclear capabilities are seen as providing the same or perhaps a higher level of deterrence as nuclear weapons deployed in Europe, this may strengthen the case for their withdrawal to the US

14 Brad Roberts, 'Emerging and Disruptive Technologies, Multi-Domain Complexity, and Strategic Stability: A Review and Assessment of the Literature', Center for Global Security Research, Lawrence Livermore National Laboratory, February 2021, 19-20. 
or complete elimination. One can envisage, for example, deployment of intermediate-range conventional hypersonic systems in Europe as substitutes for B61 nuclear bombs. In that case, the main axis of frictions may be between the US and those states that are particularly attracted to the forward deployment of nuclear weapons (even if they are not stationed on their territories), such as Poland and other eastern flank countries. These would most likely point out that Russia would treat the replacement of nuclear assets with non-nuclear ones as an invitation to escalate any crisis to the nuclear level, and that a nuclear-sharing model that includes direct involvement of a number of European allies cannot easily be replicated with regard to most of the new capabilities.

A number of other political-military challenges may arise. First, we may face the emergence of a gap in thinking about escalation management and the employment of new capabilities between the US and its allies, with consequences for the nuclear sphere. The US is likely to maintain its pre-eminence in terms of the development and deployment of new technologies, and of formulating conceptual approaches as regards their use. Since individual NATO countries, most importantly the UK and France, aim to actively contribute their own ideas and approaches to discussions on issues such as artificial intelligence development, space and cyber policy, common NATO positions can be formulated. However, the US is likely to be far ahead of the majority of NATO allies. Further, the US and other technologically advanced allies may not be willing to share the full details of some of the more sensitive technologies they possess at NATO fora. The September 2021 announcement of the creation of the trilateral security partnership between the US, Australia and the UK (AUKUS) can be seen as potentially contributing to this trend. While the initial attention was focused on the nuclear-powered submarines, the participants also pledged closer cooperation on cyber capabilities, artificial intelligence, quantum technologies and other undersea capabilities. This may lead to strengthening the links and interoperability between the three countries, but would not engage NATO (which has a broad partnership relationship with Australia) as a whole.

Consequently, in a crisis, allies may be surprised by certain US actions and their escalatory effects. This may not necessarily be caused by any lack of consultation or advanced warning but may happen because of their lack of understanding of the doctrinal, technological and military aspects of 
the US's approach to operations. ${ }^{15}$ The reverse may also be true. The US may be forced to react to developments arising from the employment of new technologies by some of its NATO allies, including a situation in which such an action escalates conflict to the nuclear threshold (e.g. cyber attack on the adversary's nuclear command and control). The alliance's response to this challenge will need to take the form of in-depth consultations, developing joint doctrinal documents and investment in simulations and wargaming.

Second, integration of new capabilities and new domains into the deterrence and defence toolbox seems inevitable. Some changes will have important consequences at the tactical and operational levels (e.g. ubiquity of low-cost unmanned systems and their increased level of autonomy and effectiveness) and some may reach the strategic level. Any sudden devaluation of nuclear deterrence due to a technological breakthrough — for example, the end of ballistic missile submarines' 'near-invulnerability'-would have major ramifications and force the three NATO nuclear possessors to re-evaluate their posture, with major consequences for the alliance. But less revolutionary changes may be significant, as they would impact on traditional NATO approaches to burden and risk-sharing, deterrence and assurance.

In the foreseeable future, a scenario of US military disengagement from NATO and Europe remains far-fetched, which means that Europe can rely on the full range of US capabilities when facing Russia. However, if the US or other allies were able to provide advanced strategic non-nuclear assets for common defence and deterrence, they may be inclined to reduce the 'traditional' contributions of their armed forces. The UK's recent Integrated Review may pave the way, as it highlights the contribution of UK offensive cyber and precision strike capabilities (as well as nuclear forces) to NATO, while simultaneously reducing the size of its land forces. Other allies may follow the same logic. For example, some of the European states currently hosting US nuclear weapons may be interested in exploring the option of providing specific new capabilities to the alliance instead of continuing with their nuclear mission. However, the question would arise as to whether such a rebalancing and new division of labour would increase the credibility of deterrence or be seen as weakening NATO's ability to provide the necessary levels of 'boots on the ground'.

15 See, for example: Justin Anderson and James R. McCue, 'Deterring, Countering, and Defeating Conventional-Nuclear Integration', Strategic Studies Quarterly 15(1), 2021, 28-60. 
Third, there is a danger of increased polarisation between the allies interested in making full use of the opportunities created by EDT and those advocating more restraint and engagement with potential adversaries as the best way to reduce the destabilising effects of new technologies. ${ }^{16}$ In the NATO context, one can expect future discussions about the deployment of specific weapon systems, which may resemble Cold War-era debates between the proponents of strengthening deterrence and pursuing arms control. For example, should NATO countries move forward with, or rather aim to limit, the deployment of certain categories of autonomous or hypersonic systems, looking for similar restraint from Russia?

Finally, NATO's adversaries will have a vote in deciding the future role of nuclear weapons and new capabilities in the alliance's deterrence mix. The further pursuit of new military technologies by Russia, and increased lethality of its own mix of offensive and defensive non-nuclear capabilities, will necessitate a periodical review and adaptation of NATO's approach. The issue will become particularly pressing if Russia manages to achieve dominance on some non-nuclear 'rungs' of escalation-for example, hypersonic precision strike systems or counterspace capabilities. The alliance may then be forced to broaden the role of nuclear weapons to maintain the credibility of its deterrence strategy, including potentially an explicit threat of nuclear retaliation to non-nuclear strategic attacks, or prepare its own non-nuclear response, using a range of new technologies.

16 For examination of the employment of EDT for bolstering deterrence, see D. Jankowski, 'NATO and the Emerging and Disruptive Technologies Challenge', in NATO in the Era of Unpeace: Defending against Known Unknowns, ed. D. Jankowski and T. Stępniewski (Lublin: Institute of Central Europe, 2021), 96-99; A. Lanoszka, 'How Emerging Technologies Might Affect Baltic Security', in The Return of Deterrence: Credibility and Capabilities in a New Era, ed. William G. Braun III, Stéfanie von Hlatky and Kim Richard Nossal (Carlisle: US Army War College Press, 2019), publications.armywarcollege.edu/pubs/3703.pdf. 
This text is taken from Alliances, Nuclear Weapons and Escalation: Managing Deterrence in the 21st Century, edited by Stephan Frühling and Andrew O'Neil, published 2021 by ANU Press, The Australian National University, Canberra, Australia.

doi.org/10.22459/ANWE.2021.10 